\title{
Long term clinical outcome of a randomised controlled trial of anterior chamber lenses after high volume intracapsular cataract surgery
}

\author{
A Hennig, G J Johnson, J R Evans, R Lagnado, A Poulson, D Pradhan, A Foster, \\ R P L Wormald
}

\begin{abstract}
Background-Age related cataract remains the major cause of blindness throughout the world. In many countries, the majority of cataract surgery continues to be done by the intracapsular cataract extraction (ICCE) method. The results of a large randomised controlled trial of multiflex open loop anterior chamber intraocular lenses (ACIOL) were reported from a busy eye hospital in Nepal.

Methods-There was a randomised controlled trial of 2000 people with bilateral cataract reducing vision to less than $6 / 36$. Interventions were ICCE with an ACIOL compared with ICCE with aphakic spectacles (+11 dioptres). Participants were followed at discharge, 6 weeks, 1 year, and $11 / 2-5$ years after surgery. Visual acuity and clinical outcome were measured. A poor outcome was defined as vision $<6 / 60$. Results-Visual outcome was comparable in the two groups. More of the control group experienced functional blindness due to loss of aphakic spectacles at 1 year. The majority of cases of poor outcome occurred in the first year after surgery. There was no indication of any lens related problems after 1 year.
\end{abstract}

Conclusion-Multiflex open loop anterior chamber lenses are safe for up to 1 year of follow up when used by experienced surgeons, and the available evidence of $2-5$ years of follow up suggests that the complication rate is reasonably low. An ACIOL at the time of cataract surgery offers benefits over routine ICCE surgery with aphakic spectacle correction as it avoids the problem of replacing lost and broken spectacles.

(Br f Ophthalmol 2001;85:11-17)

Age related cataract remains by far the single major cause of blindness throughout the world. ${ }^{1}$ Although ophthalmic surgeons in developing countries are moving progressively towards the universal use of extracapsular cataract extraction (ECCE) and posterior chamber intraocular lenses (PCIOLs), in many countries more than half the cataract surgery continues to be done by the intracapsular cataract extraction method (ICCE). There is evidence from several developing countries that many aphakic patients are not wearing aphakic spectacle correction. ${ }^{23}$ As well as the optical problems of magnification and distor- tion, aphakic spectacles are easily damaged in these circumstances and may be impossible or too expensive to replace. The question therefore arises as to whether anterior chamber intraocular lenses (ACIOLs) after ICCE could be of benefit until all surgeons are trained or retrained in extracapsular surgery with PCIOL implants, and the necessary extra equipment and supplies for this technique are available.

The intraocular lenses being considered are new high quality, open loop anterior chamber lenses. Auffarth and colleagues have shown from a study of explanted ACIOLs that the complication rates of the flexible open loop ACIOLs are much lower than had previously been assumed and should be clearly distinguished from the complications of the older ACIOL designs. ${ }^{4}$ The earlier closed loop, rigid or semirigid ACIOLs gave rise to corneal complications, increased inflammation, and cystoid macular oedema.

Following a pilot study, ${ }^{5}$ we conducted a randomised controlled trial of the new open loop anterior chamber intraocular lenses, with a control group who received ICCE and aphakic spectacle correction. The setting was a busy eye hospital in south east Nepal, where 300 outpatients were seen each day and around 10000 cataract extractions performed each year with good results. ${ }^{6}$ We have already reported visual outcome and causes of visual loss in the trial cohort for a general medical and public health audience. ${ }^{78}$ This paper summarises the visual outcome and presents peroperative, short, and long term complications in more detail.

\section{Methods}

RECRUITMENT AND SAMPLE SIZE

Patients were recruited to the trial from people presenting at Lahan Eye Hospital with bilateral cataracts reducing vision to $6 / 36$ or less, aged 40-64 years, and living within an accessible distance for follow up. Exclusion criteria were pre-existing ocular disease other than cataract (for example, age related macular degeneration, glaucoma, diabetes, or hypertension). Patients gave informed consent to participate in the trial, which was approved by the Medical Research Council of Nepal. Recruitment took place between the beginning of February 1992 and end of February 1995

We estimated that a sample size of 2000 people would give us a $90 \%$ power to detect a doubling of poor outcome at the $5 \%$ significance level. We estimated that $4 \%$ of the people given 
ICCE and aphakic spectacles would have a poor outcome after 1 year (that is, visual acuity of $<6 / 60$ ) and that we would follow up $80 \%$ of people enrolled in the trial.

RANDOMISATION

ICCE with an ACIOL was compared with ICCE with aphakic spectacles. The first operated eye was entered into the trial. This was agreed between the patient and surgeon, and was usually the eye with worse vision if there was a difference between the two. Random allocation was computer generated in London, and serially numbered sealed, opaque envelopes were prepared and sent to Nepal. They were securely stored, retrieval requiring two keys, one held by the study administrator and the other by one of the surgeons. At the time of surgery, after the patient had received local anaesthetic and was prepared on the operating table, the numbered envelope was opened in view of all the staff present.

MASKING

Masking was not attempted because of the obvious differences between the two procedures.

SURGICAL METHODS

An ophthalmic assistant performed a retrobulbar local anaesthetic block for each patient outside the operating theatre. The patient then walked into the theatre to one of the four tables used in rotation; the surgeon moving from table to table after the preparation was completed by the nurse. A loupe magnification of $4.5 \times$ was used, with good illumination from ceiling mounted lamps above each table. The horizontal corneal diameter ("white to white") was measured and $1 \mathrm{~mm}$ added to arrive at the diameter of ACIOL to be used-12 $\mathrm{mm}, 12.5$ $\mathrm{mm}$, or $13.0 \mathrm{~mm}$. An ab interno corneoscleral incision, with a small conjunctival flap, was made with a von Graefe knife. A peripheral iridectomy was made at the 10 or 2 o'clock position. A reusable cryoextractor was used for intracapsular extraction of the cataract. The anterior chamber was reformed with air, and the pupil, if still dilated, was constricted with a drop of acetylcholine. Those eyes assigned to receive an IOL had a single piece four point fixation Kelman Multiflex III ACIOL (Alcon, Hemel Hempstead, UK) inserted. Standard powers of 19.0 or 19.5 dioptres were available. A drop of hydroxypropylmethyl cellulose (HPMC) $2 \%$ was placed on the lens before insertion. At least five $8 / 0$ virgin silk sutures were used to close the corneoscleral section. In those eyes receiving an ACIOL the air in the anterior chamber was replaced with Ringer's lactate solution. In cases of vitreous loss, the vitreous was removed using small swabs and scissors or by gentle aspiration with a wide bore needle.

Postoperatively, gentamicin $20 \mathrm{mg}$ was injected subconjunctivally in the lower fornix of all operated eyes, and in those receiving an ACIOL dexamethasone $4 \mathrm{mg}$ was also injected. Chloramphenicol ointment or neosporin ointment was applied and the eye band- aged. The patients walked back to the wards with assistance. Postoperatively, topical antibiotics were used routinely three times per day, and topical steroid drops used as indicated for iritis.

FOLLOW UP

The operated eyes were examined by an ophthalmologist daily for 5 days. On the sixth day all operated eyes were examined with a slit lamp, and patients who had had ICCE without an ACIOL were then given standard +11 dioptre spectacles.

Patients were followed up at 6 weeks and 1 year after surgery. We sent out reminder cards to everyone who took part in the trial to come back to the hospital for follow up. Those who did not return to the hospital were visited in their village by an ophthalmic assistant, trained to measure visual acuity and to diagnose the main causes of blindness. We re-examined the whole cohort between November 1996 and April 1997 which gave follow up times of between 1.5 and 5 years after surgery. People not returning for this final follow up were visited at home by one of two ophthalmologists (AP or RL).

\section{OUTCOME MEASURES}

Visual acuity was measured using a modified Snellen E chart with four optotypes on each line. Vision was taken as the last line on which at least three optotypes were read correctly. Functional vision (vision used in everyday life, with or without prescribed spectacles), and best corrected vision (vision after refraction, or with a pinhole when refraction could not be performed) were recorded. A slit lamp examination and full examination of the retina was performed on all patients seen at the hospital. Cystoid macular oedema, causing poor outcome, was diagnosed according to clinical appearances on direct ophthalmoscopy and/or by slit lamp biomicroscopy with a fundus lens.

\section{STATISTICAL METHODS}

As everyone received the treatment to which they had been assigned, all analyses are intention to treat. The first eye operated was entered into the trial and so the results are presented for outcome in that eye only. Most of the measurements were categorical and estimates of the association between treatment group and outcome were made using the relative risk and its associated confidence intervals. Pearson's $\chi^{2}$ statistic was used to test for differences between the two groups. The only continuous measurement was intraocular pressure. Student's $t$ test was used to test the difference between the two groups. All analyses were done using SAS version 6.11 (SAS Institute, Cary, NC, USA) and EPI-INFO version 6 (CDC, Atlanta, GA, USA).

\section{Results}

STUDY GROUP

Figure 1 is the trial profile. There were 2908 people eligible to enter the study on the basis of having vision less than $6 / 36$ due to bilateral cataracts, and place of residence. A total of 379 
Table 1 Reasons for refusing to take part in the study

\begin{tabular}{lrr}
\hline & No & $\%$ \\
\hline Wants cataract glasses & 399 & 75 \\
Wants both eyes done now & 76 & 14 \\
Wants IOL & 30 & 6 \\
Does not want IOL & 21 & 4 \\
Cannot come for follow up & 3 & 1 \\
Total & 529 & 100 \\
\hline
\end{tabular}

were excluded because of existing ophthalmic complications or general medical reasons. Of these, 120 patients had central corneal scarring in at least one eye, and 68 had a hypermature lens in the second eye, so that early bilateral surgery was indicated. Other ocular problems included pterygium (28 people), and intraocular pressure over $22 \mathrm{~mm} \mathrm{Hg}$ (10 people). General medical problems included a blood pressure over $180 / 100 \mathrm{~mm} \mathrm{Hg}$ (32 people) and known diabetes (six people). A total of 529 people declined to take part in the study. The reasons for this refusal are given in Table 1 .

The randomisation resulted in 1002 patients receiving an anterior chamber intraocular lens, and 998 being controls. The characteristics of these two groups are displayed in Table 2. More than $98 \%$ of the patients had preoperative visual acuity in the operated eye of less than $3 / 60$. Almost all of the cataracts were either mature (white lens opacities reaching the anterior capsule) or hypermature (evidence of liquefaction of the lens contents, with swelling).

\section{CHARACTERISTICS OF SURGERY AND}

PEROPERATIVE COMPLICATIONS

An intraocular lens was inserted in $100 \%$ of the ACIOL group at the planned procedure. This was achieved after one attempt in $98.5 \%$, two attempts in $1.4 \%$ and in one case there were three attempts to insert the anterior chamber lens satisfactorily. HPMC was injected to maintain the anterior chamber in 88 patients
$(8.8 \%)$, and subsequently removed. A miotic was used in $68.2 \%$ of eyes in the intraocular lens group, but in only $0.3 \%$ in the control group. A total of $99.2 \%$ of all patients had five sutures, and 16 required six sutures. The time between placing the superior rectus muscle suture and closure of the wound was a median of 4.1 minutes in the control group (range 2.410.3 minutes) and 6 minutes (range 3.0-17.2) in the ACIOL group $(\mathrm{p}<0.001)$.

The routine Graefe section had to be extended with scissors in $2.1 \%$ of the ACIOL cases and $1.2 \%$ in the control group in order to allow for extraction of the lens. There was significant bleeding from the section in $0.7 \%$ of the ACIOL cases and $0.3 \%$ in the control group. Unplanned extracapsular extractions occurred at a similar rate in the two groups (6.8 and $7.7 \%$ respectively). The cryoprobe touched the cornea or iris in $0.9 \%$ of the ACIOL group and $0.6 \%$ of the controls. In two of the controls the lens delivered on its own, and in one case there was a subluxated lens. There was a significant difference in the rate of anterior vitrectomy performed $-2.9 \%$ in the ACIOL group and $0.4 \%$ in the control group.

\section{VISUAL ACUITY}

Table 3 show the numbers of people with severe visual impairment and blindness in the cohort over the period of the study. In the ACIOL group, at discharge from hospital, $2.2 \%$ were severely visually impaired and $1.2 \%$ were blind. The proportion severely visually impaired rose to $5.6 \%$ at 6 weeks and fell to $5.0 \%$ at 1 year. The proportion blind was $1.2 \%$ at 6 weeks and then rose slightly to $1.9 \%$ at 1 year. After refraction, $1.8 \%$ and $2.6 \%$ were severely visually impaired at 6 weeks and 1 year respectively and $1.0 \%$ and $1.6 \%$ were blind at the two time periods.

There were similar numbers of people severely visually impaired and blind in the con-

Recruitment February 1992 to March 1995

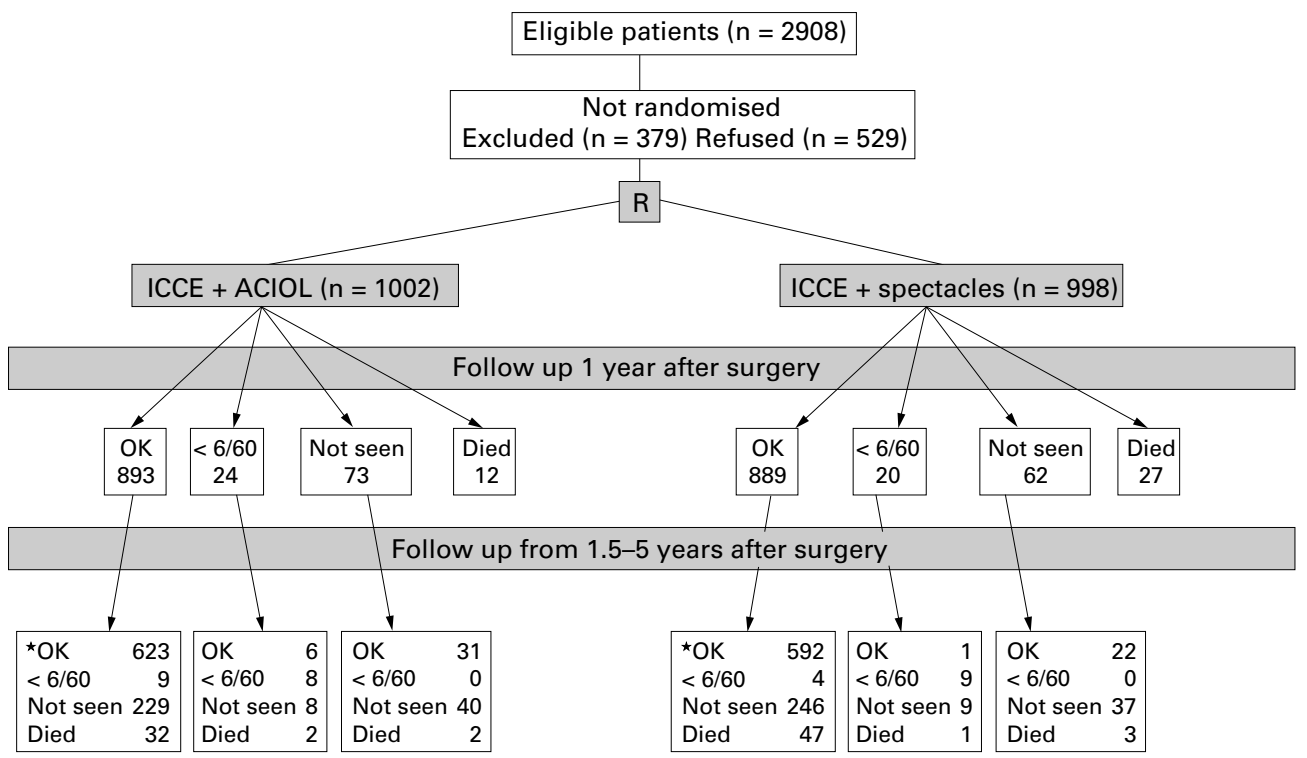

Figure 1 Trial profile. ${ }^{\star}$ Three people with normal eyes for whom no vision measurement was obtained counted as "OK" (one ACIOL, two controls). 
Table 2 Comparison between study groups

\begin{tabular}{|c|c|c|c|c|}
\hline & \multicolumn{2}{|c|}{$A C I O L$} & \multicolumn{2}{|c|}{ Control } \\
\hline & No & $\%$ & No & $\%$ \\
\hline Total number randomised & 1002 & 100.0 & 998 & 100.0 \\
\hline \multicolumn{5}{|l|}{ Age (years): } \\
\hline $40-44$ & 43 & 4.3 & 41 & 4.1 \\
\hline $45-49$ & 141 & 14.1 & 148 & 14.8 \\
\hline $50-54$ & 182 & 18.2 & 174 & 17.4 \\
\hline $55-59$ & 211 & 21.1 & 214 & 21.4 \\
\hline $60-64$ & 425 & 42.4 & 421 & 42.2 \\
\hline Male & 479 & 47.8 & 505 & 50.6 \\
\hline \multicolumn{5}{|l|}{ Occupation: } \\
\hline Household & 481 & 48.0 & 465 & 46.6 \\
\hline Agriculture & 418 & 41.7 & 413 & 41.4 \\
\hline Shopkeeper & 26 & 2.6 & 26 & 2.6 \\
\hline Other & 77 & 7.7 & 94 & 9.4 \\
\hline \multicolumn{5}{|l|}{ Religion: } \\
\hline Hindu & 864 & 86.2 & 839 & 84.1 \\
\hline Muslim & 137 & 13.7 & 157 & 15.7 \\
\hline Buddhist & 1 & 0.1 & 2 & 0.2 \\
\hline Literacy, illiterate & 796 & 79.4 & 781 & 78.3 \\
\hline \multicolumn{5}{|l|}{ Preoperative visual acuity: } \\
\hline $6 / 60$ & 1 & 0.1 & 1 & 0.1 \\
\hline $3 / 60$ & 12 & 1.2 & 19 & 1.9 \\
\hline$<3 / 60$ & 989 & 98.7 & 978 & 98.0 \\
\hline Eye operated, right & 592 & 59.1 & 581 & 58.2 \\
\hline \multicolumn{5}{|l|}{ Surgeon: } \\
\hline A & 501 & 50.0 & 499 & 50.0 \\
\hline $\mathrm{B}$ & 501 & 50.0 & 499 & 50.0 \\
\hline \multicolumn{5}{|l|}{ Type of cataract: } \\
\hline Immature & 9 & 0.9 & 10 & 1.0 \\
\hline Mature & 733 & 73.2 & 754 & 75.6 \\
\hline Hypermature & 260 & 25.9 & 234 & 23.4 \\
\hline
\end{tabular}

Table 3 Visual acuity at discharge, 6 weeks, and 1 year

\begin{tabular}{|c|c|c|c|c|c|c|c|}
\hline & $A C I O L$ & & Control & & & & \\
\hline \multicolumn{8}{|l|}{ Number followed up: } \\
\hline At discharge & 1002 & & 997 & & & & \\
\hline At 6 weeks & 987 & & 968 & & & & \\
\hline At 1 year & 918 & & 909 & & & & \\
\hline Functional acuity & No & $\%$ & No & $\%$ & $R R$ & $95 \% C I$ & \\
\hline \multicolumn{8}{|l|}{ <6/60: } \\
\hline At discharge & 22 & 2.2 & 36 & 3.6 & 0.61 & 0.36 & 1.03 \\
\hline At 6 weeks & 55 & 5.6 & 30 & 3.1 & 1.80 & 1.16 & 2.78 \\
\hline At 1 year & 46 & 5.0 & 49 & 5.4 & 0.93 & 0.63 & 1.38 \\
\hline \multicolumn{8}{|l|}{$<3 / 60:$} \\
\hline At discharge & 12 & 1.2 & 16 & 1.6 & 0.75 & 0.35 & 1.57 \\
\hline At 6 weeks & 12 & 1.2 & 22 & 2.3 & 0.53 & 0.27 & 1.07 \\
\hline At 1 year & 17 & 1.9 & 42 & 4.6 & 0.4 & 0.23 & 0.7 \\
\hline Best corrected acuity & No & $\%$ & No & $\%$ & $R R$ & $95 \%$ & \\
\hline \multicolumn{8}{|l|}{$<6 / 60$} \\
\hline At 6 weeks & 18 & 1.8 & 14 & 1.5 & 1.26 & 0.63 & 2.52 \\
\hline At 1 year & 24 & 2.6 & 20 & 2.2 & 1.19 & 0.66 & 2.14 \\
\hline \multicolumn{8}{|l|}{$<3 / 60$ : } \\
\hline At 6 weeks & 10 & 1.0 & 12 & 1.2 & 0.82 & 0.35 & 1.88 \\
\hline At 1 year & 15 & 1.6 & 16 & 1.8 & 0.93 & 0.46 & 1.87 \\
\hline
\end{tabular}

Functional acuity is defined as the vision in the operated eye with the patient's own available spectacles.

Best corrected acuity is defined as the vision in the operated eye with full correction of refractive error, or with pinhole and closest spherical refraction if a full refraction was not possible.

trol group at all follow up times. The exception to this is at 1 year when there were more people functionally blind in the control group. This occurred because of the loss of aphakic spectacles. There was a $60 \%$ reduced risk of functional blindness in the ACIOL group 1 year after surgery.

There were 13 new cases of poor visual outcome (best corrected vision <6/60) in the cohort arising after the 1 year follow up, of which nine $(1.4 \%)$ were in the ACIOL group and four $(0.7 \%)$ in the control group. Seven with poor visual outcome at 1 year had

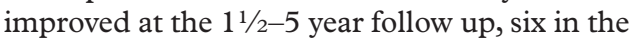
ACIOL group and one in the controls.
CAUSES OF VISUAL LOSS

There were 35 people identified at 1 year follow up as having best corrected vision $<6 / 60$ related to the surgical procedure (20 ACIOL, 15 control). The causes of poor visual outcome at 1 year in the ACIOL group were uveitis (eight), secondary glaucoma (five), cystoid macula oedema (two), endophthalmitis (four), and late corneal ulcer (one). In the control group the causes were endophthalmitis (seven), uveitis (two), corneal decompensation and ulcer (one each), and retinal detachment (four).

There were 13 new cases of poor vision after 1 year (nine ACIOL, four control). In the ACIOL group the causes of visual loss were retinal detachment (four), cystoid macular oedema (two), epiretinal membrane (one), age related macular degeneration (one), late endophthalmitis (one). In the control group the causes of visual loss were retinal detachment (two), late endophthalmitis (one), and primary open angle glaucoma with macular degeneration (one).

CLINICAL FINDINGS

The clinical findings at discharge, 6 weeks, 1 year, and $1 \frac{1 / 2}{2} 5$ years after surgery are presented in Tables 4 and 5 .

At discharge, more of the patients with an ACIOL had cells visible in the anterior chamber (95\% v 78\% in the control group), and "many cells" were seen in 3.7\% of the ACIOL group compared with $0.9 \%$ of the control eyes. This proportion with uveitis declined progressively with time. IOL tuck was seen in $7 \%$ of eyes with an ACIOL. There was no significant difference in the proportion with discomfort or corneal oedema at discharge.

There were 11 cases of endophthalmitis, four in the ACIOL group and seven in the control group. Nine of these cases occurred in a 48 hour period due to a malfunctioning autoclave.

At 6 weeks after surgery, $1.7 \%$ of the ACIOL group experienced pain compared with $0.4 \%$ of the control group, and some uveitis was seen in $20 \%$ of ACIOL eyes compared with $5 \%$ of the controls.

At 1 year after surgery, $1.0 \%$ of the ACIOL group complained of pain, and $2.6 \%$ had some degree of uveitis, compared with $0.2 \%$ and $0.5 \%$ respectively in the control eyes. IOL pupil tuck was seen in $9.3 \%$ of the ACIOL eyes. The lens was well positioned in $97 \%$ of eyes and tilted or rotated in $2.8 \%$. Intraocular pressure was similar between the two group with mean of $17.0 \mathrm{mmHg}$. The proportion of people with pressures over $21 \mathrm{~mm} \mathrm{Hg}$ was $7.1 \%$ and $9.2 \%$ in the ACIOL and control groups respectively.

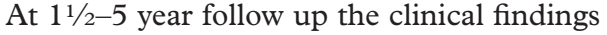
were similar between the two groups. There was a suggestion of an increased risk of raised intraocular pressure in the ACIOL group-five had a pressure of $30 \mathrm{~mm} \mathrm{Hg}$ or more compared with one in the control group but this was not statistically significant (Fisher's exact test $\mathrm{p}=0.22$ ). 
Table 4 Clinical findings at discharge, 6 weeks, and 1 year in the two groups

\begin{tabular}{|c|c|c|c|c|c|c|c|c|c|c|c|c|}
\hline & \multicolumn{4}{|c|}{ Discharget } & \multicolumn{4}{|c|}{6 weeks } & \multicolumn{4}{|c|}{1 year } \\
\hline & \multicolumn{2}{|c|}{$A C I O L$} & \multicolumn{2}{|c|}{ Control } & \multicolumn{2}{|c|}{$A C I O L$} & \multicolumn{2}{|c|}{ Control } & \multicolumn{2}{|c|}{$A C I O L$} & \multicolumn{2}{|c|}{ Control } \\
\hline & No & $\%$ & No & $\%$ & No & $\%$ & No & $\%$ & No & $\%$ & No & $\%$ \\
\hline \multicolumn{13}{|l|}{ Total given slit lamp } \\
\hline Irritation & 975 & 97.5 & 967 & 97.1 & 620 & $72.0^{\star}$ & 529 & $66.1^{\star}$ & 42 & 8.3 & 28 & 6.7 \\
\hline Pain & 9 & 0.9 & 12 & 1.2 & 15 & $1.7^{\star}$ & 3 & $0.4^{\star}$ & 5 & 1.0 & 1 & 0.2 \\
\hline Corneal oedema & 110 & 11.0 & 119 & 11.9 & 7 & 0.8 & 2 & 0.3 & 2 & 0.5 & 2 & 0.5 \\
\hline Hyphaema & 2 & $0.2^{\mathrm{a}}$ & 12 & $1.2^{\mathrm{a}}$ & 0 & 0 & 0 & 0 & 0 & 0 & 0 & 0 \\
\hline Vitreous in $\mathrm{AC}$ & 34 & $3.4^{\star}$ & 109 & $11.0^{\star}$ & 36 & $4.2^{\star}$ & 134 & $16.8^{\star}$ & 14 & $2.8^{\star}$ & 56 & $13.3^{\star}$ \\
\hline Bleb/prolapse & 1 & 0.1 & 1 & 0.1 & 3 & 0.4 & 1 & 0.1 & 1 & 0.2 & 0 & 0 \\
\hline \multicolumn{13}{|l|}{ Uveitis: } \\
\hline Few cells & 953 & $95.4^{\star}$ & 780 & $78.4^{\star}$ & 162 & $18.8^{\star}$ & 34 & $4.3^{\star}$ & 12 & $2.4^{\mathrm{a}}$ & 2 & $0.5^{\mathrm{a}}$ \\
\hline Many cells & 37 & $3.7^{\star}$ & 10 & $1.0^{\star}$ & 10 & $1.2^{\star}$ & 2 & $0.3^{\star}$ & 1 & 0.2 & 0 & 0 \\
\hline \multicolumn{13}{|l|}{ Pupil: } \\
\hline Vitreous to wound & 9 & 0.9 & 5 & 0.5 & 20 & 2.3 & 19 & 2.4 & 13 & 2.6 & 13 & 3.1 \\
\hline IOL tuck & 70 & 7.0 & 0 & 0 & 37 & 4.3 & - & - & 47 & 9.3 & - & - \\
\hline Other pupil abnormalities & 15 & $1.5^{\mathrm{a}}$ & 4 & $0.4^{\mathrm{a}}$ & 28 & 3.3 & 36 & 4.5 & 32 & 6.3 & 19 & 4.5 \\
\hline \multicolumn{13}{|l|}{ IOL: } \\
\hline Tilted & 10 & 1.0 & - & - & 9 & 1.1 & - & - & 5 & 1.0 & - & - \\
\hline Rotated & 0 & 0 & - & - & 4 & 0.5 & - & - & 9 & 1.8 & - & - \\
\hline \multicolumn{13}{|l|}{ Opacities: } \\
\hline IOL deposits & 15 & 1.5 & - & - & 27 & 3.1 & - & - & 5 & 1.0 & - & - \\
\hline Other & 7 & 0.7 & 3 & 0.3 & 2 & 0.2 & 2 & 0.3 & 0 & 0 & 0 & 0 \\
\hline \multicolumn{13}{|l|}{ IOP: } \\
\hline Mean & - & - & - & - & & - & - & - & 17. & & 17. & \\
\hline Range & - & - & - & - & & - & - & - & & & & \\
\hline$>21 \mathrm{~mm} \mathrm{Hg}$ & - & - & - & - & - & - & - & - & 36 & 7.1 & 39 & 9.2 \\
\hline$>29 \mathrm{~mm} \mathrm{Hg}$ & - & - & - & - & - & - & - & - & 6 & 1.2 & 5 & 1.2 \\
\hline Other problems & 21 & $2.1^{\mathrm{b}}$ & 38 & $3.8^{\mathrm{b}}$ & 28 & 3.3 & 26 & 3.3 & 25 & $4.9^{\star}$ & 5 & $1.2^{\star}$ \\
\hline
\end{tabular}

${ }_{\star}=\mathrm{p}<0.001 ; \mathrm{a}=\mathrm{p}<0.01 ; \mathrm{b}=\mathrm{p}<0.05$ All other data comparisons are not significant.

All numbers are expressed as a percentage of the total given slit lamp examination with the exception of "total given slit lamp examination" where the denominator is the total in the study cohort. People seen only in the village had their vision measured but were not given a slit lamp examination which is why the numbers examined in this table are lower than in Table 3.

†Four people did not have a slit lamp examination at discharge because they had had an evisceration due to endophthalmitis

Table 5 Clinical outcome at 11/2-5 year follow up

\begin{tabular}{|c|c|c|c|c|c|}
\hline & \multicolumn{2}{|c|}{$A C I O L$} & \multicolumn{2}{|c|}{ Control } & \multirow[b]{2}{*}{$p$ Value } \\
\hline & No & $\%$ & No & $\%$ & \\
\hline Total number randomised & 1002 & 100 & 998 & 100 & \\
\hline Total number seen at $1 \frac{1 / 2}{2}-5$ years of follow up & 677 & 67.6 & 628 & 62.9 & 0.03 \\
\hline \multicolumn{6}{|l|}{ Years of follow up: } \\
\hline$<2$ & 54 & 5.4 & 44 & 4.4 & NS \\
\hline $2-<3$ & 263 & 26.2 & 226 & 22.6 & NS \\
\hline $3-<4$ & 205 & 20.5 & 196 & 19.6 & NS \\
\hline $4-<5$ & 142 & 14.2 & 158 & 15.8 & NS \\
\hline$>5$ & 13 & 1.3 & 4 & 0.4 & NS \\
\hline \multirow{2}{*}{ Total number given slit lamp examination } & 674 & 67.3 & 625 & 62.6 & 0.03 \\
\hline & $N$ & $\%$ * & $N$ & $\%$ * & \\
\hline \multicolumn{6}{|l|}{ Discomfort: } \\
\hline Irritation & 25 & 3.7 & 19 & 3.0 & NS \\
\hline Pain & 14 & 2.1 & 9 & 1.4 & NS \\
\hline Corneal oedema & 7 & 1.0 & 5 & 0.8 & NS \\
\hline Hyphaema & 0 & 0.0 & 1 & 0.2 & NS \\
\hline Vitreous in AC & 22 & 3.3 & 110 & 17.7 & 0.001 \\
\hline Bleb/prolapse & 2 & 0.3 & 0 & 0.0 & NS \\
\hline \multicolumn{6}{|l|}{ Uveitis: } \\
\hline Few cells & 0 & 0.0 & 0 & 0.0 & NS \\
\hline Many cells & 1 & 0.1 & 0 & 0.0 & NS \\
\hline No red reflex & 0 & 0.0 & 0 & 0.0 & NS \\
\hline Peaking of pupil, distortion due to IOL & 398 & 59.1 & - & - & NA \\
\hline \multicolumn{6}{|l|}{ IOL: } \\
\hline Tilted & 10 & 1.5 & - & - & NA \\
\hline Rotated postoperatively & 16 & 2.4 & - & - & NA \\
\hline \multicolumn{6}{|l|}{ Visual axis opacity: } \\
\hline Deposits on IOL & 5 & 0.7 & - & - & NA \\
\hline Other opacities & 14 & 2.1 & 8 & 1.3 & NS \\
\hline \multicolumn{6}{|l|}{ Macula: } \\
\hline Cystoid macular oedema & 11 & 1.6 & 6 & 1.0 & NS \\
\hline Other problem & 57 & 8.5 & 48 & 7.8 & NS \\
\hline \multicolumn{6}{|l|}{ Retina: } \\
\hline Retinal detachment & 5 & 0.7 & 5 & 0.8 & NS \\
\hline Other problem & 7 & 1.0 & 6 & 1.0 & NS \\
\hline \multicolumn{6}{|l|}{ IOP: } \\
\hline Mean & 14 & & 14.7 & & NS \\
\hline Range & & & $4-$ & & - \\
\hline$>21 \mathrm{~mm} \mathrm{Hg}$ & 11 & 1.6 & 7 & 1.1 & NS \\
\hline$>29 \mathrm{~mm} \mathrm{Hg}$ & 5 & 0.7 & 1 & 0.2 & NS \\
\hline \multicolumn{6}{|l|}{ Glaucoma: } \\
\hline Primary & 2 & 0.3 & 0 & 0.0 & NS \\
\hline Secondary & 5 & 0.7 & 2 & 0.3 & NS \\
\hline Other problem & 4 & 0.6 & 6 & 1.0 & NS \\
\hline
\end{tabular}

${ }^{\star}$ Expressed as a percentage of total given slit lamp examination. 


\section{Discussion}

A limitation of this clinical trial is the loss to follow up after 1 year, with $62-67 \%$ of patients in the two trial groups having a slit lamp examination. It was difficult to persuade these elderly patients to return more than 1 year after the surgery. The second limitation is the difficulty in diagnosing primary and secondary glaucoma as a complication of surgery in the absence of visual fields, which were not available. The reported incidence of this complication therefore needs to be taken as a minimum as more subtle cases may have been missed.

When compared in a randomised trial with the outcome of intracapsular cataract extraction and spectacle correction, the use of anterior chamber lenses in this setting is safe and yields equivalent visual results. It should be emphasised that this is a situation of high volume surgery where the two surgeons operated on alternate days, each performing approximately 50 operations in a morning. This was made possible by having four operating tables, and good assistance from ophthalmic medical assistants and nurses.

At the beginning of the study, the main reason why people refused to take part was that they wanted aphakic glasses. Others wanted both eyes operated at the same admission. As the trial progressed a number of patients started to ask for the intraocular lens and so they were not prepared to be randomised.

Almost all the operated cataracts were mature or hypermature, and the visual acuity of the operated eye was usually between hand movements and perception of light. The Graefe section was rapid and effective in the hands of these experienced surgeons and in this situation. The complications at surgery were as expected, with approximately $7 \%$ unplanned extracapsular extraction. Viscoelastic was used in less than $10 \%$ of cases, as the surgeons are experienced with implanting IOLs under air, and the use of consumables is kept to a minimum in order to reduce cost. More anterior vitrectomies were done in those eyes in which an intraocular lens was going to be inserted. Conversely, there were more control eyes with vitreous in the anterior chamber at follow up, presumably because the surgeon had judged vitrectomy not to be essential. Of the 11 trial patients who suffered endophthalmitis nine occurred during a 48 hour period. All surgery was stopped until the source of this infection was identified, which was traced to a faulty portable autoclave.

The high rate of follow up is noteworthy. Each patient was followed to their village if they did not return. The control group had significantly more eyes with an acuity less than $3 / 60$ at 1 year follow up due to lost or broken spectacles $(4.6 \% v 1.9 \%)$. This is despite the ready availability of low cost aphakic spectacles at Lahan hospital. This complication of lost spectacles will increase over time. It is recommended by some surgeons to give two pairs of aphakic spectacles routinely to anyone not having an IOL. This has cost implications for the programme. In this context it was only pos- sible to give a standard power aphakic correction, as more complex spectacle prescriptions are not affordable to the majority of people. The difference that a full correction of refraction, including cylinder for astigmatism, would make to poor outcome is shown between the figures for "functional" and "best corrected" acuity in Table 3.

At 1 year $7.1 \%$ of operated eyes had an IOP greater than $21 \mathrm{~mm} \mathrm{Hg}$ in the ACIOL group compared with $9.2 \%$ in the control group; however, this had fallen to $1.6 \%$ and $1.1 \%$ respectively at long term follow up. Five eyes $(0.7 \%)$ receiving an ACIOL were diagnosed as having secondary glaucoma at more than 1 year follow up, compared with two eyes $(0.3 \%)$ in the control group.

Retinal detachment at more than 1 year follow up occurred in $0.7 \%$ of the ACIOL eyes and $0.8 \%$ of the control eyes. Cystoid macula oedema was diagnosed in $1.6 \%$ of the ACIOL group (11 eyes, of which four had an acuity of less than $6 / 60$ ), and $1.0 \%$ of the control group (six eyes of which no eye had an acuity less than $6 / 60$ ). There was no case of visual loss due to corneal decompensation in the ACIOL eyes.

The long term follow up at between $11 / 2$ and 5 years confirmed the impression gained at 1 year that these high quality, flexible open loop anterior chamber intraocular lenses cause relatively few visually threatening complications and can be used safely by experienced eye surgeons in the setting of high volume cataract surgery in Asia. An ACIOL after cataract surgery offers benefits over routine ICCE surgery with aphakic spectacle correction as it avoids the problem of replacing lost and broken spectacles. The complications of uveitis and secondary glaucoma are probably the result of the positioning of the lens in the anterior chamber, and cystoid macula oedema because of the ICCE technique. These complications are likely to be less with an extracapsular procedure (ECCE) and posterior chamber intraocular lens (PCIOL), providing that the surgeon is trained and equipped for this technique. The long term incidence of posterior capsule opacification and its management after ECCE with PCIOL in the context of high volume surgery on patients from rural areas is still to be defined. The safety of ACIOLs in other settings, particularly Africa, needs to be evaluated as the complication of uveitis as reported by Cook et al may be greater in more pigmented eyes.

The study was executed by Albrecht Hennig and Damodar Pradhan who conducted all the operations; Ruby Lagnado and Arabella Poulson conducted the clinical examinations at the $1 \frac{1}{2}-5$ year follow up. They were assisted in the design and execution of the study by (in alphabetical order): Jennifer Evans, Allen Foster, Gordon Johnson, and Richard Wormald. The data were analysed by Jennifer Evans, Albrecht Hennig, and Allen Foster; the paper was drafted by Gordon Johnson. All authors commented on the paper.

We are grateful to all the patients who took part in the trial and without whom the study could not have been conducted. We acknowledge the contribution of the following: Bindeshwar Mahato coordinated the study in Lahan. Kedar Timilsina, Manato coordinated the study in Lahan. Kedar Timilsina, Janardan Khatiwada, Ganesh Prasad Updahaya, Mahendra Mahato, and Ramchandra Pasman assisted in the recruitment of patients and execution of the trial including data collection. Kristina Hennig managed the data entry and databases in Kathmandu. Richard Gregson provided clinical support to the surgeons and monitoring of the project on several visits. At vari-
ous times over the course of the study members of the Steering 
Committee included Noel Rice (chair), Dr RP Pokhrel, Dominic Negrel (WHO), Bjorn Thylefors (WHO), Christian Garms (CBM), and Professor Richard Hayes who also advised on the statistical analysis of the study. Alcon (UK) generously donated the lenses. The study was funded by Christoffe Blindenmission/Christian Blind Mission International.

1 Thylefors B, Negrel A-D, Pararajasegaram R, et al. Global data on blindness. Bull World Health Organ 1995;73:11521.

2 Bucher PJM, Ijsselmuiden CB. Prevalence and causes of blindness in the northern Transvaal. Br F Ophthalmol 1988; 72:721-6.

3 Directorate General of Health Services (ophthalmology section). Present status of national programme for control of blindness. New Delhi: Government of India, 1992.

4 Auffarth GU, Wesendahl TA, Brown SJ, et al. Are there acceptable anterior chamber intracoular lenses for clinical use in the 1990s? An analysis of 4104 explanted anterior chamber intracoular lenses. Ophthalmology 1994;101: 1913-22.

5 Hennig A, Pradhan D, Gregson RMC, et al. Intra-ocular lens implantation during cataract surgery in Nepal. Lancet 1993;341:375-5.

6 Hennig A, Shrestha SP, Foster A. Results and evaluation of high volume intracapsular cataract surgery in Nepal. Acta Ophthalmol 1992;70:402-6.

7 Hennig A, Evans JR, Pradhan D, et al. Randomised controlled trial of anterior-chamber intraocular lenses. Lancet 1997;349:1129-33.

8 Evans JR, Hennig A, Pradhan D, et al. Randomised controlled trial of anterior-chamber intraocular lenses in Nepal: long term follow-up. Bull World Health Organ 2000;78:3728.

9 Cook CD, Evans JR, Johnson GJ. Is anterior chamber lens implantation after intracapsular cataract extraction safe in rural black patients in Africa? A pilot study in KwaZuluNatal, South Africa. Eye 1998;12:821-5. 